when the diagnosis of smallpox was made. The patient was removed as quickly as possible to the quarantine hospital. One nurse, who was not nursing the patient, but who was in the room but a few minutcs, contracted smallpox. This shows the possibility of infection during the early stages. I have in mind another case of a young man, who, in probably the first day of the eruption of the disease, picked up a child and carried it a short distance. This child, his nephew, was in due time taken down with smallpox, the result of this exposure.

Note.-The following resolution was adopted by the joint Sections on Practice of Medicine and Hygiene and Sanitary Science, after the above discussion:

"Resolved, By the joint Sections on Practice of Medicine and Hygiene and Sanitary Science, That the disease now prevailing extensively in the linited States and called in some instances 'pseudo-smallpox' is genuine smallpox, and should be so treated with vaccination and quarantine by all health authorities. Carried."

\section{CANCER OF THE UTERINE NECK.}

\section{WITH COMMENTS ON THE PRESENT-DAY TEACHING.*}

\section{J. M. BALDY, M.D.} PHILADELPHIA.

Cancer of the neck of the womb is practically incurable. This statement is made advisedly and the proof of its correctness lies in the reports of results of treatment from all quarters of the world. At the present time there is no cure for cancer short of surgery, and it is no abuse of language to state that this disease is surgery's disgrace. Such statements I am well aware will be callod radical by timid men or by men of little knowledge, they will be called bold by even men of knowledge and experience, but it will be a bold man indeed who can conscientiously call them untrue. I repeat that cancer of the neck of the womb as far as results go to-day is practically incurable. It is a reproach to our art, nay it is even a reproach to ourselves, but still unpalatable as the statement may be, it is the full truth. No amount of juggling with figures or facts will alter this state of affairs, nor will spurious nor exaggerated claims make matters better for those of us who want the truth and not garbled statistics. It will do little good to ostrich-like bury our heads in the sands of self-complacency, accept statements made from any and every source and sit with our hands folded whilst our patients die. What man of large experience carl look over the past dozen years of his practice and put his fingers on any considerable number of patients who have suffered from this disease and are alive to-day? Who but can count the dead by scores, and this despite any and all methods of treatment known to us?

It is not possible to state with any degree of accuracy the exact proportion of such cases which it is possible to save, but judging from the past it is an absolute, although lamentable fact that it is less than 5 per cent. The best statistics on this subject with which I am familiar in this country which pretend to sufficient accuracy to be of any value have come from Johns Hopkins Hospital. T'heir cases cover all which have come to that institution since the institution began its work. On the face of these statistics 20 per cent. or more of such patients are cured-and this is a small claim as such claims go-at least such is the impression given the profession, although the facts are there and any one can deduct the real truth from them himself if he so chooses. As these statistics are a fair representa-

* Read at the Fifty-second Annual Meeting of the American Medical Association, in the Section on Obstetries and Diseases of Women, and approved for publication by the Executive Committee of the Section: Drs. A. H. Cordier, W. E. B. Davis and Henry P. tion of all other reliable reports both from home and abroad, it may be well to examine them somewhat critically and draw our own and probably different deductions as to percentages. The facts are there and we are just as capable of judging the results and forming conclusions as are their compilers.

Seventy-three cases of cancer of the cervix were operated upon: 15 cases, or somewhat over 20 per cent. are alive to-day. But then, 68 cases were rejected as nonoperable-incurable-all of whom are of course dead to-day. Consequently, when we draw our own conclusions they are that a little ever 10 per cent. instead of over 20 per cent. of cases of cancer of the uterus which have come to that institution are alive to-day.

Nor is this all. It will be recalled that Johns Hopkins Hospital has availabe a magnificent pathological department and that all gynecological cases passing through that institution have a thorough and systematic overhauling by men specially trained and skilled in this work. Patients are freely examined under ether, all curette specimens are examined microscopically and every safeguard as far as can be is thrown around the diagnosis. The consequence is that a diagnosis is not infrequently made in cases where the disease is so early as not to have been suspected and in a few where the diagnosis is even then (after the microscopic examination) doubtful the patient is given the benefit of the doubt. It is no news to the pathologists to state that there is often a wide difference of opinion amongst them as to what is and what is not cancer in the very early stages of the disease. Not infrequently we find men claiming certain minute changes as surely malignant; whilst others say perhaps (but not certain) and still other say not at all. What is the practical deduction in all this? Simply that the man who operates as the result of the microscopic examination and gives his patient the benefit of any doubt. occasionally operates on a case which is not cancer and which of course has no recurrence. This is exactly what they do (and properly so) at Johns Hopkins. Is it then out of the way to think that probably there may be a case or two (or even more) amongst the 15 patients of that institution who are still alive who would come in this category? If even a single such case exists in that group what then becomes of the 10 per cent. of cures?

Nor is this all; probably the most serious aspect of the danger of these statistics remain to be considered. Fifteen cases are reported alive. Analyse that statement for one moment and see what a false impression it gives. Of these 15, 9 have only passed from 10 months to two and one-half years since their operation. Only 6 cases alive from 3 to 6 years after their operation. Who can say that every one of the 9 cases under two and one-half years will not die of the disease in the next two and one-half years. Even the 6 who are alive after three years are by no means safe. These same statistics report a number of cases who have died four and one-half and five years after the operation.

What now becomes of the 10 per cent. cures? Am I too radical when $I$ state that less than 5 per cent. of cases of cancer of the womb are cured? I would probably be nearer the real truth if I said 2 per cent. In view of these facts am I not justified in my opening remarks that "cancer of the neck of the womb is practically incurable?" The same analyses of the recent statistics from Germany gathered and reported by Winter shows almost exactly the same results, although reported for entirely the opposite effect. 
If those then be the facts what is the remedy, or is there any remedy? It matters little what the line of treatment, be it medical or surgical, although the surgical side of the question is the one which appeals to me, the remedy to my mind is plain: 1, a full realization of the facts as they stand, and 2, a sound understanding as to the importance of the early discovery of the disease.

The tendency of the teaching in the schools of to-day is in these respects bad; if I may be candid, abominable. $I$, in no way, mean to state that the facts of the present day teaching are unture, but I do mean to say that the tendency is to lay such undue stress on certain points as to practically obliterate from the ordinary medical mind the more important and vital points. The two particular points to which I refer are the statistics and the use of the microscope for diagnostic purposes. We well know that there are periods of fads in medicine as well as in other affairs of life and that these fads often result in disaster in more ways than one. This question of the laboratory is rapidly becoming a dangerous fad, and unless there is a halt the coming generation of doctors will be incompetent to early distinguish this disease and will show even worse results in cancer of the cervix than our own.

Let me illustrate for a moment what I mean by the two abuses to which I have referred. It must be apparent to everybody, if we wish for better results, that the earlier the diagnosis is made and the earlier the case is brought to the surgeon the greater the chance of a cure. This appears to me to be axiomatic. It then behooves those of us who know the truth about the results of treatment to bring this matter home in no indecisive manner to the minds of the present and future practitioner of medicine into whose hands these cases first come. It behooves us no longer to deceive him directly or indirectly, consciously or unconsciously. If we are to continue to indirectly deceive him by our statistics in talking and writing of 20 to 60 per cent. of cures when we are fully conscious that when the whole group of cases be studied together, as they in all fairness should be, the percentage of real cures is from 2 to 5 per cent. only, what are we to expect from him?

First, a great laxness in the attempt to discover these cases early; second, a disinclination to hurry them at once to the surgeon, because forsooth his conscience is easy in the supposed knowledge that when he does decide to send them a large percentage can be saved at any rate. In other words. he is not impressed with the terrible nature of the disease and the almost certain fate which awaits his patient. Quite the reverse is the result of the teaching of the day; his mind rests easy, his patient rapidly approaches inevitable death and we who should enlighten him as to the real truth sink hin deeper in his complacency by feeding him with our statistics of successful operations, ourselves as successful operators. They may not be direct falsehoods, but they are the more dangerous in that they have a semblance of truth and are indirectly most abominably deceptive.

If he knows that of all the cases of cancer of the cervix it falls to his lot to see in practice but from 2 to 5 per cent. at most are permanently cured, he will become the more cautions in his observations, will discover these cases the earlier and when a case is once suspected will be the more likely to seek consultation at once, both for the sake of his own reputation as well as for the safety of his patient. Once beginning to watch all his female clientele with this object in view, will he place his dependence on the laboratory and the microscope for his diagnosis? Far be it from me to decry these valuable aids to modern medicine or to belittle all that has been and is being done by the laboratory men, but far be it from you even indirectly to decry the clinician and all he has done and is doing in the way of acute observation and deduction from accurately observed facts. The clinical observation of facts comes before the laboratory examination: the laboratory examination is an impossibility without the prior clinical work and is after all at best corroborative; it rarely originates. Few cases of cancer of the cervix are diagnosed by the microscope where the diagnosis is not possible by the clinical study of the case. Had the case not been strongly suspected of cancer the aid of the microscope had never been sought. The few exceptions to this have occurred in routine examinations of specimens in well appointed institutions with all modern advantages in the way. of appliances for teaching and study. It may be claimed that this is the goal for which we should all strive; that such examination and study should be made universal. The millennium has not yet come nor is it yet in sight, consequently we are forced to content ourselves with being practical (rather than theorists) and accepting situations as they exist obtain the best practical results from them possible. For instance, we are faced by these indisputable facts:

The great bulk of the profession live away from the teaching centers and laboratories and have few or no facilities for such routine work. They have not time for it. They have not the special knowledge necessary to make it of much use. They have not the apparatus. There are few communities in which there is even a single man with the requirements necessary for this work, to whom it might be referred. What is the use then of laying so much stress on the microscope to the belittling or exclusion of methods which are within the reach of all practitioners where ever they be, and upon which they must of necessity rely? I mean by this the clinical study of cancer patients, be the disease early or late. The most recent book on cancer of the uterus (Cullen), a work which is based on the accumulated experience of one of the great teaching institutions of medicine in this country (Johns Hopkins), a useful work for the specialist who can read between the lines and who can not be contaminated by its false teaching, a work which should be excluded from the hands of every practitioner of medicine (other than specialists) in the land, has this to say on the subject of diagnostic symptoms (our only apparent hope of advancement in the treatment of this disease): "After thoroughly analyzing our own cases, and studying the records of others, we find that diagnostic symptoms at best are meagre, and in the early stages give little or no clue to the real nature of the disease." The teaching throughout the whole book is consistent with this statement and it is sad to relate that this fairly represents the tendency of the teaching on this subject to-day, not only in this great medical institution, but in many others. No greater mistake was ever made; no falser teaching was ever promulgated than this. The statement is absolutely without foundation in fact, and if any of us arrive at a similar conclusion it is because we have allowed the laboratory craze to blind our best judgment and obscure our acuteness of observation, to say nothing of blunting our reasoning faculties. Quite the reverse is true. The symptoms of early cancer are as plain as those of any other disease in its early stages and the reason it is not oftener detected early is the fault of the observer, 
not of the symptoms had they been properly observed and interpreted. And it is just such teaching as is contained in this book (all microscopic, nothing clinical) which will make careless men more careless and untaught men ignorant. I repeat that the symptoms of cancer, although meager in the verv carly stages, are sufficient, and it has been the rare case indeed in which the microscope has made the diagnosis that a retrospect of the case has not caused great surprise at the number of symptoms present and their significance. I protest against such teaching and look in the future for a return from the will-o-the-wisps of the laboratory to the sound ground of educated and accurate clinical observation. It is not my intention to drift into an exhaustive study of the symptomatology of early cancer of the uterus, but there are a few points to which I will refer briefly.

There are three great symptoms of cancer, pain, odorous discharges, hemorrhages; these taken in conjunction with progressive loss of flesh and strength present a picture which becomes so significant that no one is justified in failing to see their significance. This picture complete is however the picture of well-advanced cancer and is never present in the disease in its early stages. Hemorrhage with possibly beginning loss of flesh and strength is the diagnostic sheet-anchor in the early stages. No one knows how early bleeding begins, but begin it does very early; early enough to give plenty of warning of what is coming. In this connection there are one or two circumstances which should be considered almost pathognomónic, so few are the exceptions. They at least should make the suspicion so strong as to demand a most careful and immediate overhauling of the patient.

A woman once having passed the menopause, the menstruation having entirely ceased and a year or two, or six or more years later but a single show of blood from the genitalia be noticed no matter from what supposed cause (traumatism excluded), cancer will be found with but rare exceptions. Personally I have never found an exception.

Even during the menstrual life of a woman, if a blood stain be noticed after coition; if after the use of a syringe a stain appears or the water is bloody; if following excitement or exercise, or from any similar cause: if a slight stain be observed in the mornings on arising or following constipation (reasonable cases being excluded), cancer should always be suspicioned and a mistake will rarely be made. It is true some non-cancerous ulceration and mucous polypus will cause this symptom, but rarely.

These symptoms are so readily observable and are so significant that it is a mystery how often they are ignored and the patient allowed to drift into an incurable state. They are so plain that he who runs can read. Not so with others which, although taking a little more acuteness of observation, are none the Iess significant.

All women from puberty to the menopause bleed, fortunately with more or less regularity. The bleeding itself is not so significant as the comparison with what it has always been before in the same woman. Naturally, then the man who can make the most valuable comparison is the one who is familiar with all the details of the woman's menstrual life-the family doctor. It is quite easy for such a man to know almost any irregularity in a woman's bleedings, to know of any reasonable cause for such irregularity, to compare such irregularity with the past and to consider it in conjunction with the present state of general health. pro- gressive or persistent otherwise unexplained loss of strength or flesh. Being always on the look-out and suspicious for his patients, being always determined in every case to exclude cancer where the symptoms (irregular bleeding) are not readily explainable by other lesions, as a careful man always considers and excludes pregnancy in any abdominal growth, how could the case escape a suspicion where the bleeding from the woman's genitalia becomes profuse or comes at unusual times. It is not so much the quantity of blood lost which is important as the fact that blood eren in minute quantities is observed at times not expected and which is incompatible with the physiologic flow or a prolongation of this function (due so often to a neoplasm or an inflammatory lesion.) Any or all these points are significant and call vigorously for a careful examination. They may be readily explained at the examination by a polyp or an erosion or a benign ulceration, but most frequently cancer will be found; early often, even so early that the laboratory man will decline to make a positive diagnosis from any small specimen you may present to him; so early at times that he will be uncertain while you will be so certain that you will operate on the case in spite of his hesitancy. Many a time have $I$ done this, many a time I hope and expect to do it again. In few cases have I ever found that after a careful and prolonged study of the removed organ he (the pathologist) has not finally fully agreed with my diagnosis--so far superior is clinical observation and deduction to the microscope in this disease. So far convinced am I of the truth of this position that in cancer of the uterus I never expect to allow the microscope to stay my hand-no matter what its decision may bc. If it agrees with my clinical deduction well and good; if it is uncertain and hesitates, it is not going to prevent me trying to save the life of the patient.

I repeat that all our statistics on cancer of the cervix uteri (or rather the interpretation of them) are false and grossly misleading. The microscope as a means of diagnosis is vastly inferior to clinical symptoms and observations.

The teaching of the day in most of our great schools of learning in the respect is as bad as it well can be; consequently the outlook for competent observers and diagnosticians for the future is bad.

$$
\text { prscussion. }
$$

Dr. J. H. Carstexs, Detroit, Mich-There is no one who has been more inclined to become pessimistic in reference to the discussion of cancer than 1 , but I feel grateful that $I$ have not become such a pessimist as my friend Baldy. I am not at all astonished that he can not show a greater number of permanent recoveries if he absolutely discards laboratory investigation. If he waits until as the result of the smell and the discharge he can make a clinical diagnosis. if he waits that long, there is no wonder that the number of recoveries will be very small indeed. Our object has always been to get these cases early, and if vou wait until you can smell the bacillus or until you can hear them sing. your patients will certainly die inside of a year. When you have a woman who flows more than she ought for two, three or four months, curette that uterus and carefully examine the curettings with your microscope. You will find that it is probably a benign adenoma. The hemorrhage will probably recur in spite of your curettage. You curette again two or three months afterward and find that your case is a malignant adenoma; then is the time to operate. If you wait another three months and again examine the serapings with your microscope, you will find that it is an adenocarcinoma. Then it is too late to try to save the woman's life. Farly investigation and early operation is the 
proper thing to do. I will give Dr. Baldy every opportunity to look at a little plug removed from a lacerated cervix and tell me whether it is malignant or not, but I know that some of these cases are malignant before $I$ have them examined microscopically, and if $I$ get the report that they are malignant, then I take out that uterus within four weeks. In that way I save the woman's life. If I wait until I can smell it, then an operation will do no good. The trouble is, we get them too late. $I$ can show you cases operated on ten years ago, where the microscope showed beyond question that it was a cancer, in which there has been no return of the disease. Other cases that seem to be just as mild or milder would have a recurrence in situ or some other part of the body within a year. We can not tell by the appearance of a case whether there will be a return. Sometimes the most favorable cases will recur and the most unfavorable cases will have no recurrence. What I plead for is early diagnosis; then we will have fewer recurrences.

DR. J. G. ClaRK, Philadelphia-Three great objections can be raised to Dr. Ialdy's paper. The first objection, a very strong one, is that the paper comes from a man who has not gone into the pathologic side of the question, a man who criticises from the standpoint of one far removed from the scientifie aspect of this subject. The second objection, also a very potent one, is that the statistics of others are taken as his basis for criticism. Why does he not bring forward his own statistics? Third, a special point he made, he does not recall a single instance in which he ever took out a uterus which he diagnosed clinically as a carcinoma, and which was proven to be otherwise after that. If he absolutely excludes the micro. scope as a factor in diagnosis, I would like to know how he can tell whether or not he made a mistake.

Dr. Baldy has attacked the work of Dr. Cullen, and as he is not present $I$ feel that I must say a word in his defense. One of the first things Dr. Cullen brought out in his book is the clinical side of these cases. He dwells especially on the three eardinal symptoms of carcinoma; then he says in a general way that failing in this we should curette and examine the scrapings microscopically, because the microscope is unquestionably superior to our ordinary crude diagnostic methods. In this way we can positively determine whether or not it is a eareinoma. If there is any one point which I lay stress upon in my lectures and in my clinical demonstrations to students, if there is one thing I try to impress on these men, it is the early diagnosis in these cases of carcinoma, a fact which Dr. Baldy himself has alluded to. Wherever there is a typical discharge, wherever there is anything out of the ordinary in a woman of a carcinoma age, that is a case for careful clinical study. Then, when in doubt, or where there is none, resort to the microscope, and if it confirms our diagnosis we can be absolutely certain of our convictions.

The surgical aspect of the subject is a weak one. We have done our best in a general way for carcinoma. I am certain that on the microscope must hinge the final diagnosis of these eases, especially where there is doubt. The negative factor is often greater than the positive factor. Within the last three months I have had two cases, in one of which, at least, from the clinical standpoint, no man could say it was not a carcinoma. The woman was 39 years old, had had periodical hemorrhages for several months, and had had a carcinoma of the breast. The first curettage showed areas that were suspicious, but I felt safe and waited three or four weeks for a recurrence of the hemorrhage to again curette so as to be absolutely certain before making a major operation. A second curettage absolutely showed the benign nature of the case, a simple inflammatory condition of the endometrium. Since the last curettage, five months ago, there has been no hemorrhage. The positive factor is the confirmation of the diagnosis through the microscope. The negative factor is the ruling out in just such eases as this. Many a woman will have her uterus removed if we are guided solely by clinical symptoms. I have never seen a single instance where Dr. Cullen was mistaken when he said that a certain case was carcinoma. I have seen cases where he was in doubt, but in those cases the carcinoma was so little that it was better to wait two or three weeks and then be able to say positively that this is carcinoma. If it is a benign tumor you can let the woman go with a simpler operation.

Dr. E. G. ZiNke, Cincinnati, Ohio-Dr. Baldy's paper deserves praise for the manner of its presentation rather than its contents. There is plenty of room for just criticism. I want to limit myself to the consideration of two points: The question of early diagnosis, and the curability of cancer of the cervix. If Dr. Baldy's description of the early symptoms of cancer is correct, then I have never known what the early symptoms of cancer of the cervix are. The symptoms given by him mark an almost hopeless condition. The early diagnosis, in the majority of cases of cancer of the cervix, is exceedingly diffcult; and it is for this reason that these cases come to us, usually, when too late. I saw a striking example, in 1891, in Chrobak's clinic in Vienna. A weil-nourished, rosy-cheeked woman, aged 29, was brought into the clinic one day, and, after the professor had made an examination, he asked that the patient be taken out of the room. He then turned to his audience and said: "Gentlemen, I am sorry to say that this poor woman is hopelessly lost to the ravages of a carcinoma coli." The symptoms present in this case would not have warranted the suspicion even of the existence of this disease.

Several years ago I saw three women in one year (aged respectively, 23,26 , and 27 ), every one of them seemingly a picture of health, yet all hopelessly lost to cancer of the cervix. They were being treated for irregular menstruation, menorrhagia, metrorrhagia, etc., by their physicians. They did not suspect malignaney. These cases were reported, at the time, to the Cincinnati Obstetric Society, and published in the Journal of Obstetrics and Diseases of Women.

As to the possibility of curing these cases: I am convinced that they can not be cured unless the disease is removed by the knife in the earliest stage. Occasionally a patient, advanced in years, recovers even though the disease was extensively present. Carcinoma coli seems less violent and rapid in its progress when it occurs in advanced than in early life. An early diagnosis of cancer of the cervix is only possible when examinations are made promptly and thoroughly in every instance when complaints or irregularities point to the internal genitalia for their site or origin.

I believe in the curability of cancer of the uterus. The disease must, however, be attacked early and completely removed. I have seen good results follow the removal of the uterus in seemingly hopeless cases. Too many cases are abandoned as incurable. Every case should be treated until the last.

Dr. EmIL RIEs, Chicago-The statistics which Dr. Baldy attacked, teach a very eloquent lesson, and the way Dr. Baldy has disfigured them and juggled with them in order to fit them into his logic is astonishing. He starts out to prove that carcinoma of the cervix is incurable, and then figures on cases that come to the hospital when they are already incurable. Ho mixes up the incurability of cancer if left alone, with the incurability if operated. Of course, those cases not operated are incurable; they are lost; everybody admits that; no one ever said they were curable. If he uses those statistics he can only take those cases that were operated. That 15 or 20 per cent. of the cases are operated and survive for a time, merely proves just what that means and no more. But to take into consideration the cases not operated, and to attempt to prove with them that cancer is incurable, is an injustice. The injustice is the more severe because it strikes a man and a work which are worthy of the highest praise. Cullen's work on cancer of the uterus is excellent because it teaches the im. portance of laboratory work in spite of Dr. Baldy. Every modern man must subscribe to what Dr. Cullen says concerning laboratory methods and the necessity of the microscope in the early diagnosis of carcinoma. The man who does not agree with him is antiquated.

The doctor fails to talse into account that there is a new operation which proves the cure of carcinoma to be possible. has proven it to a certain extent already, and is going to prove it still more in the future. It also explains why such a large number of cases which are operated on under the old methods have recurred. I speak of the method which I had the honor 
of proposing six years ago, and which has been followed in Europe as well as in this country and Canada. This method consists of the complete removal of the regional lymphatic glands, together with the broad ligaments, round ligaments, utero-sacral ligaments, tubes, ovaries and uterus. When I proposed this operation I suspected that the glands would be involved early in earcinoma. Most gynecologists teach that in carcinoma of the uterus the glands are not infected early. They know nothing about it, because they have not examined the glands. Very few men have; Cullen is one of them; Wertheim, of Vienna, is another, and I have examined a few. A number of men have examined these glands but have found no carcinoma. Suffice it to say that those who have not found carcinoma have not examined all the glands or they would certainly have found the carcinoma.

As to results, Wertheim has operated on fifty cases, but he went far beyond my indications. His mortality from the operation has been high, therefore he comes back to what I have always said, limit the operation to the early cases, as it gives you a much better chance of curing the patient completely. What is the result of all cases operated on in the last two years? Not one has recurred. We all know that recurrence takes place in the majority of cases within six months. I have operated on a number of cases, the oldest over four years ago, and it has not recurred. I saw the patient a month ago and she is well. The results of the Johns Hopkins operators in this work are not valuable. I do not know whethcr their cases have recurred nor is anything known about the glands in those cases. In Wertheim's cases and in mine, the glands were carefully examined.

The objections to this operation are first, high mortality. The mortality is about 20 per cent. in the hands of skilled operators. What is the mortality without the operation? Dr. Baldy says 95 per cent. If you want to give your patient a chance, operate on her. It has been said that you can not remove all the glands and connective tissue. That is a mistake. It can be done if you kecp at it. Practice the operation on the cadaver before you do it on the living. Learn the anatomy perfectly and then operate. You can clean out the pelvis as completely as you can the axilla. It has also been said that these glands may not be carcinomatous. My reply is that the case which has been examined thoroughly and which did not contain earcinoma, is still to be shown, but the cases in which the uterus was freely movable and the carcinoma small, where the case appeared to be a favorable one for vaginal removal, and where the glands were not enlarged but did contain carcinoma, are cases that have been shown by Wertheim and myself.

The last objection is that the carcinoma might be beyond the glands so that even if we removed the glands we did not remove the entire earcinoma. That is true. If the carcinoma is in the liver we can not remove it, but by removing the glands you give your patient a better chance for a complete and radical cure.

Dr. E. E. Montgomery, Philadelphia-We should weicome anything that throws light on this subject, whether through increased clinical knowledge or increased observation with the microscope; as yet we know little about the progress of carcinoma. There are cases in which the disease has extensively involved the cervix and where it is questionable as to the wisdom of an operation. I have seen cases where I have hesitated, but removed the nterus nevertheless. One of the patients is living after six years, and another two years, without any recurrence in either case. I have seen other cases in which there was apparently but little involvement and in which 1 looked forward to a most favorable result. Within six months after the operation the patient would have a recurrence of the disease and die.

The importance of an early diagnosis has been impressed on us, and I fully enclorse this; yet there is no means of determining the early presence of carcinoma. The recurrence of hemorrhage, the presence of a foul discharge, the existence of pain, not infrequently occurs after the disease has made great progress and has extended so far that even a radical operation offers but little hope. I recall a case in which there was noth- ing to indicate the existence of a malignant disease, and yet the cancer had passed through the cervix. The external os looked healthy, but the cervical wall was infiltrated. I operated, but the disease recurred in the vaginal wall in different places, affording an opportunity for seven operations during the last three and a half years, the seventh resulting fatally. I repeat, therefore, that any means which aftords us increased knowledge with regard to the development of cancer of the uterus, whether it comes through the microscope or through elinical observation, is welcome.

Dr. G. B. MASSEY, Philadelphia-In selecting an operation for eancer of the cervix we should bear in mind the progress that has been made in the determination of the causes of eancer. This is now practically established to be a protozorn, a low form of animal life. That fact should direct your attention to the method of operating which I have referred to before, by which the dissemination of the oxychlorids of mexcury in the midst of the growths eauses immediate necrosis. It is a major operation and is done under anesthesia. Of course, certain risks are run because of the separation of the eschar, but there is no immediate risk because of the absence of hemorrhage. I have one case of cancer of the cervix to operate upon in which there has been no recurrence atier about five years. In another case I obtained palliative results lasting six months. It has also been used as a palliative measure in two cases that were evidently inoperable. It relieved the pain and stopped the hemorrhage and odor, but uid not save the life of the patient.

Dr. J. Wesley Bovee, Washington, D. C.--I think that Dr. Baldy is correct in saying that this disease is incurable. We must all admit that the ultimate mortality rate is very high. I would not, however, take quite so gloomy a view of it as he does, nor am I willing to forget the microscope as a diagnostic measure. I always required that these cases should be early ones, and a case does not need to be much advanecd for me to throw it out. If we were all to follow that line we would have better results. I have done fifteen radical operations along the line mentioned by Dr. Ries. 1 did fourteen without a death, and the fifteentl and last case died on the table, so that the primary mortality rate is not any higher than that of ordinary abdominal work. I do not know whether we can go deep down in the pelvis and remove all the glands. I begin above, ligating the ovarian vcssels, slitting down along the ureters, separating it down to bladder, ligating the uterine arteries near origin and cleaning out the pelvis as well as I can. I remove all the appendages, the ligaments. the uterus and the vagina down to the vulva; dissecr out the glands, etc., and pull them out from below, following the plan of Werder. I do not know whether I remove all the glands, but $I$ am sure that the method gives better results than any other. Thus far I have had two recurrences, but it takes time to determine whether we will have as many recurrences from this method as from the others. Certainly they are fewer compared with other procedures for the same amount of time.

Dr. Gustar Kolischer, Chicago-Dr. Baldy"s manner of handling statistics is perfectly correct. Last year, Winter used the same statistics for another purpose, and this year he made a similar report which shows that the figures mentioned by Baldy are absolutely correct. In cases where a carcinoma of the cervix must be dealt with, the best operators do not have a better percentage of definite cures than 5 per cent. Most of our statistics are absolutely useless because they do not distinguish between a carcinoma of the cervix, the intermediate portion and the vaginal portion. We know that all cancers of the portio are relatively harmless; in fact, statisties show that they achieve about 20 per cent. of cures. All these cases of cancer of the cervix are cases in which we can get better results than 5 per cent.

I think Dr. Baldy was carred a little too far in denouncing the microscope. Even masters of microscopy admit that there are a great many cases in which they are absolutely unable to decide whether or not there is a carrinoma. If we have a case where the woman has hemorrhages and is losing flesh, and if the microscopist who examines the scrapings which we have obtained by curettage, tells us that he is not sure whether or not 
there is a carcinoma, are we going to wait three or four months until he is able to decide positively? By no means, we should at once do a hysterectomy. Whether our results will be improved by abdominal operation or vaginal operation, can not be decided on at the present time. Wertheim and others report that in a great many cases the glands are infected. Men like Fraenkel, and others, say that in cases of carcinoma of the portio the glands are rarely ever involved. 'I'he only statistics which are valuable, those of Wertheim, are too small to decide on this question. He has only 49 cases, and in 15 the perimetrium was not examined at all. Ten years ago I gathered 250 operations for carcinoma of the breast, and it showed that cleaning out the axilla had nothing at all to do with the results. The results improved after we began the removal of the peetoralis. Baldy's outlook is certainly a very gloomy one. If we make a distinction between carcinoma of the portio and carcinoma of the cervix our results are certainly better. If the gentleman stated that he cured hopeless cases, I am unable to see how he did it. Hcpeless cases are inoperable cases and can not be quoted. There is another point in which I think Dr. Baldy was misquoted; he said carcinoma of the cervix was incurable and that we have to remove the whole organ.

Dr. Frederick Holme. Wiggin, New Yolk City-We are all under obligations to Dr. Baldy for ealling the attention of general practitioners once more to the primal importance of thoroughly investigating and determining the cause of the trouble in every case which comes under their observation of a woman who complains of suffering from menstrual irregularities tending to an increased loss of blood, regardless of her age; even if she does not also complain of having pain in the region of the uterus or of a foul smelling discharge. It should be constantly borne in mind that these last symptoms instead of being indieative of the early stages of malignant uterine disease are those of the late or incperable stages of the disease. If we are to have a lessened mortality from this fearful disease and better results than are at present ohtained from radical operations performed for the relief of patients suffering from malignant uterine disease, the eondition must be recognized early and the surgeon called in and allowed to operate without delay. During the last few years I have had a large number of patients referred to me suffe.ing from this ciisease where it had progressed to a hopeless condition from an operative point of view, while they were under the care and observation of their family physician; he had really paid little or no attention to their complaints, had made no local examination till long after the patient had repeatedly called his attention to her troubles: the physician satisfied himself with writing a preseription for some simple medicine or ointment for piles, especially when the patient called attention to the fact that her nightgown was often slightly stained with blood in the mornings, or was told in the same ofthand way that her trouble was due to change of life, and that if she would only be patient all would come right of its own accord. When these patients finally succeeded in getting their physician to examine them, on winich they said that they did not wish to insist too strongly for fear of being considered immodest, he found much to his consternation evidence of advanced nalignant lisease too late for radical operative procedures to be undertaken with much hope of permanent benefit, whereas if the patient had only been examined carefully when she first complained, the condition might readily have been recognized and permanent relief afforded.

This is certainly a sad state of things, and should not be allowed to eontinue. Physicians should not satisfy themselves and their patients by prescribing simply a remedy to hide the symptoms complained of, but should study them, and by careful investigation seek for their cause; they should cure their patients by having the cause removed when possible, and make a proper charge for their then really valuable services. In my experience many of the careless acts of physicians in regard to their patients is due not to lack of knowledge, but to the ridiculously small fees which they are in the habit of receiving for their services; consequently they feel that they can not afford to give much time for the consideration of the case of any one patient.
In regard to the removal of tissues in cases of suspected malignant disease for the purpose of confirming the diagnosis, I have in the past, several times seen bad results follow it, especially where there had been some delay in getting a report from the microscopist, for even during that short interval of time, owing to the slight operative interference, the case had passed from an operative to an inoperative stage. Therefore, I beiieve it wisest as a rule, where the history and clinical evidences of the disease are fairly clear, to operate first and then to have the microscopical examination of the diseased organ made afterwards.

Dr. J. M. Duff, Pittsburg-Our discussions are certainly for the benefit of the general prastitioner as well as for that of the specialist. The idea that pain and hemorrhage are always symptoms of carcinoma of the uterus is certainly false and misleading. Some of the worst cases I have ever seen did not have any hemorrhage until very late, and others equally as bad did not have any pain. I know of one case where the woman did her lousework until the evening before she had a severe hemorrhage, ending in death. If we lengthen a woman's life by operating, we benefit her. But if we do not get the cases early, we can not expect to obtain as good results, even in the lengthening of life. It is our bounden duty to always seek for the cause of trouble when a patient comes to us. Lt $t$ us not be satisfied, until we find out what is the cause of any symptom. This will very frequently lead us to an examination of the genitals and there you will find the seat of disease. Very frequently that disease is cancer. In such way we can get hold of it early. Ordinarily, as the cases come to us from the general practitioner, the microscope is really not needed so far as diagnosis is concerned, because the clinical findings are sufficiently prominent to give us positive assurance as to the existence of cancer.

DR. BALDY, closing the discussion--It is impossible to answer all the eriticisms of my paper. Dr. Kolischer has answered so many of them so well as to have almost taken the words out of my mouth. Dr. Clark objected to my paper for three reasons: 1, because I did not judge from a pathologic standpoint; 2, because I aid not bring forward my own statistics and base my paper on them; 3 , that Cullen's book dwelt fully on the clinical aspect of cancer. If Cullen dwelt on the clinical aspect of cancer in his book, he himself does not know it, because he apolegizes for not having done so in unmistakable words and anyone reading the book will fully appreciate this fact.

As to my own statistics, ny paper is based on them, and Dr. Clark himself has heard me state in public discussion a number of times that $I$ do not know but the rare case of cancer of the cervix that $I$ have ever seen that was alive to-day. These two objections are therefore incomprehensible to me. I fail also to understand the objection as to my not judging from a pathologic standpoint, as I began to study that aspect of the question long before Dr. Clarke graduaterl in medicine.

As to the microscope work being valuable in its place, I have not one word of criticism to offer. No man who will read my paper in his leisure hours, will find any criticism of laboratory work or the microscope. Most of the speakers have misunderstood the entire drift of my paper. Dr. Bovee misinterprets the meaning of my use of the word "fad" in connection with the microscope. One can use words in order to bring out a certain meaning more strongly without condemning a method. One's opinion must not be judged by a single word, but by the whole of what he says. It is a dangerous thing to quibble in literature, as we are frequently caught by it. of course, the microscope is the final test, but who will use the microscope if they have not first mane the clinical test. What do these gentlemen mean?

To curette every woman who consults them and to examine the scrapings? They will hardly dare to go beyond doing this to suspected cases. I believe that a man's clinical judgment is better than a doubtful microscopical report in nine cases out of ten. Dr. Clark informs us that Cullen can always diagnose cancer with the microscope, and he eites a case in which the microscope showed a cancer, etc. The best pathologists differ from this opinion and my experience with all I have any knowl- 
edge of is that they dilfer great? and are oft: $n$ mistaken. I had a patienr come to me recently, I curetted and sent the scrapings to a prominent pathologist. He called it cancer. I sent it te another, who said he could not see anything suspiciou. of cancer, and advised me to wait three months. I concluded not to wait, so [ performed a hysterectomy. I took the speci mens to the pathologist who then admitted that it was cancer. The pathologist is no better than we are. He makes the same mistakes and has the same weaknesses.

I deny that I have juggled statistics; it is perfectly fair to considt $\mathrm{I}$ eases deseribed by other surgeons, as I have in my paper. The juggling is by the other man, and men usually object to having such manipulation exposed. I have my compliments as yet io pay to the gentleman who talks of removing the pelvic glands in operation for this disease. Dr. Rics admits 20 per cent. mortality in his operation, an enormous mortality, and that in the hands of an expert. What would it be in the hands of an inexpert? Consider a monent, where does a cancer of the cervix recur? It invariably recurs at the site of the wound where the cancer was removerl. It does not recur in the glands that are inches away from the uterus. That is the rare method of recurreuce. You might just as well remove the glands in the neek and axilla. That is common sense and practice versus theory. The proposition to remove the glands is an absolute impossibility. The surgeon does not live to-day who can remove all the glands in the pelvis of any living woman. I have thrown out that cha!lenge before and I throw it out again and it will be only a short time when every one of these gentlemen will admit that what $I$ say is true. It is all theory, but it is all wrong piactically.

I fail to understand my friend Carstens. He has built up his own theory, and then knocked it down; but it has nothing to do with my paper, as I have said practically what he says. He misunderstands the drift of my paper entirely. If he did not grasp the fact that I was pleading with the general practitioner to learn clinical liagnosis, and with the teachers to teach the general practitioner to be able to diagnose these cases early, then my papcr, as far as he is concerned, has been an utter flat failure; and I suspeet from you discussion, most of you who have discussed the papers, are as much at sea as Carstens. That was the only object I had in presenting the paper. 'leacher's should teach good clinical medicine and not too much micro. scope, so that the general practitioner would be aule to suspect these cases, and then give the microscopist a chance. It is the only hope we have for the future as far as this disease is concerned.

\section{ACUTE MASTOIDITIS AETER SUBSIDENCE AND WITHOUT RECURRENCE OF- TYMPANIC INFLAMMATION.* HIRAM WOODS, JR., M.I). BALTIMORE', MD.}

The symtornatology of acute mastoiditis is so generally known that it is almost useless to write of it. Two modes of onset are most common. While otorrhea continues, or increases in amount, mastoid symptoms develop. This, in my experience, is the rule. Less frequently otorrhea ceases, perhaps gradually, more commonly, suddenly, with simultaneous lighting up of mastoid disease. Politzer, in his text-book, says that only once has he seen suppuration in the tympanic cavity cease, while the symptoms of inflammation in the mastoid continued undiminished. And again he states: "Occasionally cases are observed in which, several days after local symptoms disappear, abscess formation in the mastoid process is manifested." In the clinic of the Presbyterian Eye, Ear and Throat Hospital of Baltimore, so far as I find recorded. there have been only

* IRead at the Fifty-second Annual Meeting of the American Medical Association. in the Section on Laryngology and Otology. and approved for publication by the Executive Committee: Drs. Emil Irayer, W. E. Casselberry and J. N. Mackenzie. two such cases in twenty-two years: one, a child three years ago, where there was no otorrhea; the other a woman, during the past winter, in whom mastoiditis required operation three weeks after recovery of all ear symptoms and restoration of good hearing. Both were treated by my associate, Dr. J. F. Crouch. The following three cases have come under my own care within the past two years:

CASE 1.-Anne W., 8 years of age, was referred to me Dec. 14, 1899, by Dr. I. E. Atkinson of Baltimore. For six days the child had been somewhat deaf, with occasional pain in the right ear. For three days there had been a discharge. There was an indefinite history of aural trouble two years previous. Prior to the present attack the child had had coryza. She heard the watch at three inches in the left; contact, right car, conversational voice about two feet. Stiff neck, the head inclined to the right, was markid. I here was a small perforation in the lower anterior quadrant of the nembrane, while the anterosuperior angle was congested. There was no pain. Politzerization was used in the office, and the ear irrigated with warm boric acid solution every third hour for two days. On the third day there was no otorrhea, and neither spontaneous nor pressure mastoid pain. Temperature during the entire course did not go above 100 . On December 26 , nine days after otorrhea had ceased, the little girl came to my office complaining of pain in the right mastoid region. There was tenderness on pressure. Torticollis was still present. There was no $\mathbf{r} \in$ dness or swelling of the mastoid. The ear was dry, the drumbead showing no evidence of renewed tympanic disease. My voice in loud whisper was heard at 20 feet. Rest, cold locally, and calomel were employed. On the 27 th there was no pain. But for the stiff neck and general lassitude the child seemed well for the next three days. During the night of the 30th, she awoke with pain referred to the mastoid. On the 31 st, the canal, membrane and tympanum showed no evidence of trouble. The mastoid was tender, rod, and hearing the same as four days previously. 'The next day, Jan. 1, 1900, I operated under chloroform. Necrosis was found on the cortex, near the tip. leading into a shallow but vertically large eavity containing only a drop or two of pus in the lower part, and filled for the rest with granulations. This whole cavity was not over a quarter of an inch deep. Its floor was exposed dura, covered with granulations. The cavity was cleaned carefully. When $I$ began to work up into the antrum and tympanum, $I$ found the latter apparently shut off. I refrained from opening into these cavities because of the disappearance of tympanic symptoms nine days before. improved hearing in the ear since otorrhea had ceased; shallowness of the process. exposed dura, and. finally, Politzer's authority for the correctness of not entering the antrum as a routine in acute cases. Recovery was uninterrupted. Torticollis was gone in three days, and after three weeks the ear had normal hearing, with the wound entirely closed.

CASE 2.-Harry G., 14 years old, was brought to me by his father. a physician in one of the counties near Baltimore, on February 23 last.The boy's history was sore throat, for nine days, with earache on both sides for about half this time. There had been slight left otorrhea, and there was still a little moisture in the left canal. The malleus plexus in each drumhead was injected, Shrapnell's membrane showing the degre? of congestion usually seen in a subsiding acute otitis media. The right membrane was intact, the lfft had a nearly healed perforation in the anterior-superior angle. Neither aural nor mastoid pain was present. Temperature was 100.6 ; the pu'se 90. Hraring was reduced to moderately raised voice at four feet, and watch on contact. 'l he boy was put to bed, given a dose of salts. and a few drops of a solution of cocain and atropia instilled into the ear. In twenty-four hours the temperature was normal, the ear free from discharge. To March 4 , eleven davs. he was given politzerization, and astringent throat applications. Then there was normal appearance of the drumhrad, and hearing had increased to whisper at ten feet. watch R. $36 / 36$; I. $24 / 36$. He now returned to his home. 